\title{
Geothermal aquifer performance assessment for direct heat production - Methodology and application to Rotliegend aquifers
}

\author{
J.-D. van Wees ${ }^{1,2,{ }^{*}}$, A. Kronimus ${ }^{3}$, M. van Putten ${ }^{1}$, M.P.D. Pluymaekers ${ }^{1}$, H. Mijnlieff ${ }^{1}$, \\ P. van Hooff ${ }^{1}$, A. Obdam $^{1}$ \& L. Kramers ${ }^{1}$ \\ 1 TN0 - Geological Survey of the Netherlands, P.0. Box 80015, 3508 TA Utrecht, the Netherlands \\ 2 Utrecht University, Tectonics group, Faculty of Earth Sciences, P0 Box 80021, 3508 TA, Utrecht, the Netherlands. \\ 3 Present address: German Chemical Industry Association, Mainzer Landstrasse 55, 60329, Frankfurt/Main, Germany. \\ * Corresponding author. Email: jan_diederik.vanwees@tno.nl
}

Manuscript received: January 2012, accepted: August 2012

\begin{abstract}
In this paper we present a probabilistic fast model for performance assessment of geothermal doublets for direct heat applications. It is a simple yet versatile and multipurpose tool. It can be well applied in better understanding the sensitivity of performance to key subsurface parameters and depth trends therein, and for assessing the probability of success for geothermal projects under technical and financial constraints.

The underlying algorithms deliver a sensible accuracy given the uncertainties associated with geothermal projects at exploration state. A public release of the software, available under the name of DoubletCalc, is easy to handle and requires a limited set of input parameters. Thanks to an open source code, DoubletCalc can be implemented in other software applications and extended as it has been implemented for the integration into the national geothermal information system in the Netherlands (ThermoGIS, 2011).

Apart from its application for site assessments, the tool can be integrated into automated workflows processing faster representations of key aquifer properties and capable to produce indicative maps for predicted doublet power, economic feasibility and prediction of cumulative amount of heat that can be recovered. These capabilities are specifically important for decision support for policymakers while assessing the effects of particular insurance schemes and funding mechanisms.

DoubletCalc cannot and is not intended to substitute geologic exploration approaches. As exploration measures, such as seismic surveys are cost intensive, DoubletCalc can be used to focus geothermal exploration on areas and sites where an enhanced probability of success can be expected.
\end{abstract}

Keywords: Geothermal energy, performance assessment, aquifer

\section{Introduction}

A geothermal doublet is the technical method selected for extracting geothermal energy from the underground for the purpose of district and greenhouse heating. In principle, the performance prediction of a geothermal doublet at a given site is to be evaluated by a reservoir model acting as a base for a reservoir simulation. Reservoir simulations facilitate the prediction of brine mass and volume flows, the energy extraction, the temperature and pressure evolution as well as the lifetime of the reservoir in question in a probabilistic manner. Such an approach is restricted by two aspects: 1) applying a reservoir simulation is a complex procedure and requires considerable resources for purchasing and maintaining corresponding software codes; and 2) sufficient data to set up a reliable conceptual reservoir model are in most cases not available at the initiation of a geothermal resource assessment. To overcome these restrictions a simplified methodology has been developed for performance calculations of doublet systems and has been made publicly available as a software tool called DoubletCalc. This compact and easy to use tool allows a probabilistic-based site-specific performance prediction of a geothermal doublet 
based on a moderate set of geotechnical input parameters. The software and the source code are available in the public domain at www.nlog.nl/nl/geothermalEnergy/DoubletCalc.html.

The methodology of DoubletCalc follows the logic of a so called fast model (Fig. 1; Van Wees et al., 2010), capable of predicting technical and economic performance indicators within a matter of seconds, under simplified model assumptions regarding reservoir behaviour, cost engineering and economics. In addition, a Monte Carlo sampling approach allows the fast model to analyze the effect of subsurface uncertainties on performance characteristics (e.g. Van Wees et al., 2010). As a result, DoubletCalc simulates a doublet's behaviour and underlying uncertainties with an accuracy compatible with a performance assessment at early exploration stages.

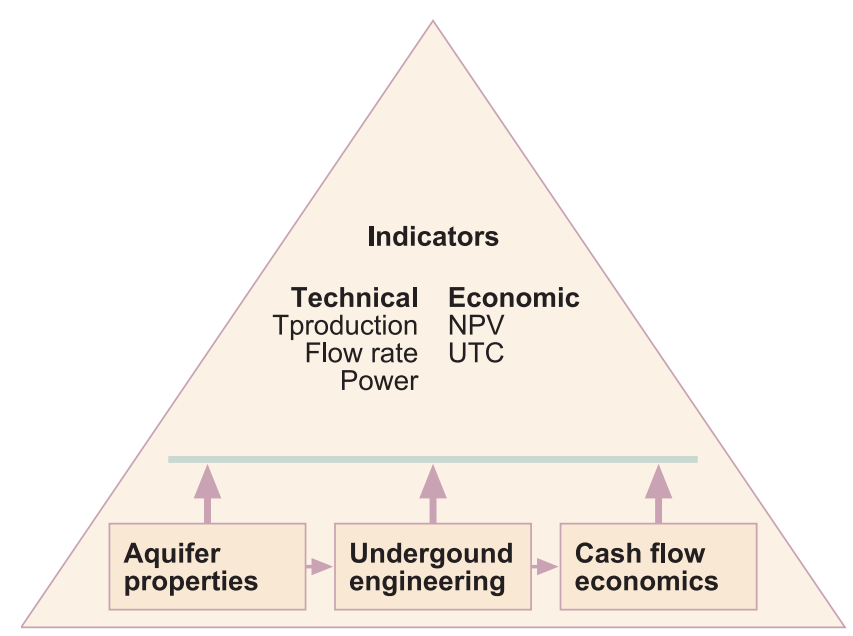

Fig. 1. Integrated value-chain probabilistic fast model capable of assessing the impact of uncertainty in technical and economic parameters based on asset's key performance indicators. Note that the model integrates a number of different physical compartments, including aquifer hydrogeological properties, engineering options and cash flow economics (after Van Wees et al., 2010).

In order to explain the methodology and added value of the techno-economic assessment approach with DoublectCalc, this paper is subdivided in two main sections. The first section focuses on the methodology, description of the underlying physics and cash flow algorithms of the fast model. The second section presents application areas of the technical and economic calculations for site specific assessment and regional potential assessment purposes. The latter are based on subsurface aquifer property data of the Netherlands, derived from detailed geothermal aquifer characterisation (Pluymaekers et al., this issue). A presentation of the results for regional potential estimates is provided by Kramers et al. (this issue).

It should be stressed that the application of DoubletCalc for geothermal potential assessment primarily targets clastic sedimentary environments where a reliable and statistically representative porosity vs. depth correlation exists. It does not apply very well to consolidated carbonates.

\section{Methodology for performance calculation}

The most important key output parameter within the scope of the technical performance computation is the geothermal power. The geothermal power $\left(\mathrm{P}_{\mathrm{ww}}(\mathrm{Wth})\right)$ extracted by the surface heat exchanger at a given temperature drop $\left(\Delta \mathrm{T}_{\mathrm{ww}}\right)$ is given by:

$$
\mathrm{P}_{\mathrm{ww}}=\mathrm{Q}_{\mathrm{m}} \mathrm{c}_{\mathrm{p}} \Delta \mathrm{T}_{\mathrm{ww}}
$$

where $Q_{m}(\mathrm{~kg} / \mathrm{s})$ is mass flow and $c_{p}$ is heat capacity. The temperature drop is equal to the difference of the production temperature and the reinjection temperature. It is assumed that the reservoir temperature is known.

The major three underlying boundary conditions for calculating the doublet power are: mass balance, pressure (impulse) balance and energy balance. For the mass balance the doublet is acting as a closed system, in which Qm from the aquifer into the producer and from the injector into the aquifer is considered constant. Figure 2 shows a scheme of the doublet including the system nodes, which are used for the performance equations detailed below. Therein, the node numbering presented in Table 1 is used.

The pressure balance is valid for the doublet as a whole. To derive volume flow, a constant pump pressure $\Delta \mathrm{p}_{\text {pump }}$ is applied to the loop, which is required to overcome pressure losses. For the nodes of the system, this requires the sum of the pressure difference overall system nodes to be zero. It takes into account the following aspects:

- Pressure losses due to fluid flow in the aquifer from the producer to the injector;

- Pressure variations in the vicinity of the producer and injector due to 'skin';

- Pressure loss in the producer and injector due to friction between the brine and inner casings;

- Pressure effects due to gravitational forces.

The hydraulic resistivity at reservoir level in association with the well design is generally the most significant component of pressure losses in the loop and is defined as (Verruijt, 1970; Dake, 1978):

$$
\Delta \mathrm{p}_{\mathrm{w}, \mathrm{aq}}=\mathrm{p}_{\mathrm{w}}-\mathrm{p}_{\mathrm{aq}}=\mathrm{Q}_{\mathrm{v}} \frac{\mathrm{\mu}}{2 \pi \mathrm{kHR} \mathrm{R}_{\mathrm{ntg}}}\left(\ln \left(\frac{\mathrm{L}}{\mathrm{r}_{\text {out }, \mathrm{w}}}\right)+\mathrm{S}\right)
$$

where:

$\mathrm{p}_{\mathrm{W}} \quad$ well pressure $(\mathrm{Pa})$

$\mathrm{p}_{\mathrm{aq}} \quad$ initial hydrostatic pressure at a well inflow in the aquifer $(\mathrm{Pa})$

$\mu \quad$ brine viscosity (Pa s)

$\mathrm{k} \quad$ permeability $\left(\mathrm{m}^{2}\right)$

$\mathrm{H} \quad$ aquifer thickness penetrated by the well (m)

$\mathrm{R}_{\text {ntg }} \quad$ net to gross ratio (-)

L lateral well distance (m) 


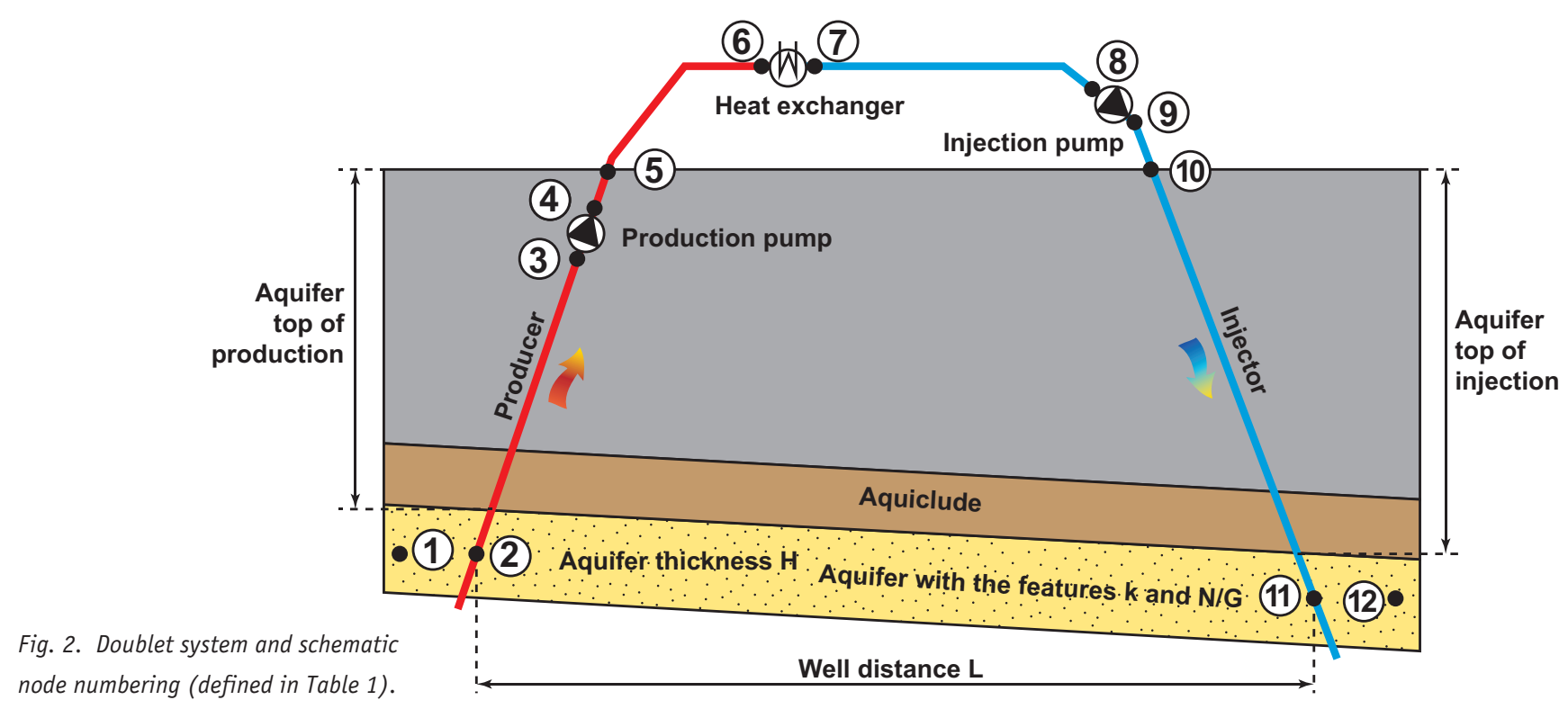

$\mathrm{r}_{\text {out, } \mathrm{w}}$ outer well radius (m)

$\mathrm{S} \quad$ skin factor (-)

$a_{v} \quad$ volumetric flow rate $\left(\mathrm{m}^{3} / \mathrm{s}\right)=\frac{Q_{m}}{\rho}$

Here, the water density $\rho\left(\mathrm{kg} / \mathrm{m}^{3}\right)$ is a function of pressure, temperature and salinity. As pressure and temperature are unique at any node within the doublet, the volume flow is varying as well. The distance $\mathrm{L}$ between wells at aquifer level is chosen such that thermal breakthrough is prevented during system lifetime. Typically, the well distance is in excess of $1000 \mathrm{~m}$ and can be estimated using analytical approaches applying a dependency on reservoir thickness (Gringarten, 1978).

Equation 1 is valid for steady-state flow to vertical well filters and for homogeneous aquifer properties. For calculations of the density $(\rho)$ and viscosity $(\mu)$ of the brine in the producer, the initial pressure and temperature of the aquifer at the producer is used. Calculation of these brine properties in the injector (see Annex) is based on the fluid pressure in the injector and the outflow temperature of the heat exchanger (= injection temperature) corrected by the depth-specific heat exchange of the producer with the surrounding geosphere. The doublet is considered as a closed mass-constant system, with salinity kept constant in all doublet elements. Equation (2) delivers the pressure change as a consequence of fluid flow in an aquifer with homogeneous properties. Our calculations, adopting simplified constant mobilities for the injector and producer well, do not significantly affect doublet wellhead steady state pressures compared to more sophisticated 2D and 3D simulations adopting variable density and viscosity evolution in time. However, properties close to the well are often deviating from those present in the rest of the aquifer due to drilling and well completion (skin effect; Van Everdingen, 1953). A skin-associated pressure drop is often created by drilling fluid residues or by partial well clogging due to fine particles (e.g. clays from the aquifer). Well stimulation aims at mitigating skin-related
Table 1. Definition of the system nodes depicted in Fig. 2 and the doublet elements between the nodes.

\begin{tabular}{lll}
\hline Node & Definition & $\begin{array}{l}\text { Element present } \\
\text { between the } \\
\text { current and } \\
\text { following node }\end{array}$ \\
\hline 1 & Aquifer at its half thickness at the producer & Aquifer \\
2 & Lowest point of inflow at the producer & Tubing/pipe \\
3 & Inflow into the production pump & Pump \\
4 & Outflow of the production pump & Tubing/pipe \\
5 & Top of the producer & Pipe \\
6 & Inflow into the heat exchanger & Heat exchanger \\
7 & Outflow of the heat exchanger & Pipe \\
8 & Inflow into the injection pump & Pump \\
9 & Outflow of the injection pump & Pipe \\
10 & Top of the injector & Tubing/pipe \\
11 & Outflow of the injector & Aquifer \\
12 & Aquifer at its half thickness at the injector & - \\
\hline
\end{tabular}

pressure drops, preferably towards removing near well damage and increasing (negative skin) well performance accordingly. The pressure modification due to skin is represented by:

$$
\Delta \mathrm{p}_{\text {skin }}=Q_{\mathrm{v}} \frac{\mathrm{\mu}}{2 \pi \mathrm{kH}} \mathrm{S}
$$

The skin factor is dimensionless. A positive skin leads to a pressure loss, while a negative skin enables enhanced flow rates without enhancing pump pressures. Negative skin can also be achieved through sub-horizontal drilling, hydraulic fracturing, or natural factures in the system (e.g. carbonates).

The pressure loss in the pipes is generally less than those involved in hydraulic resistivity of the reservoir. Calculation details are given in the annex. The dependence of $\Delta p_{\text {pump }}$ on 
the volume flow $\left(Q_{v}\right)$ is neglected. The producer always requires a pump because of the pressure conditions in the well, otherwise underpressure would prevail. The implementation of an injection pump is optional. Due to pump technical issues, implementation of an injection pump can enhance the pump's efficiency. In DoubletCalc a production pump is considered only. This results in a negligible deviation in brine density in the pipes between the outflow of the production pump and the inflow of the injection pump. The user input on the pump pressure in case of the application of an injection pump represents the sum of the pump pressures of the injection and production pumps. In this case, the pump efficiency combines both pumps efficiencies.

The production temperature calculation takes into account the effects of heat loss to the walls of the production well and is detailed in the annex. This temperature loss is generally in the order of a few degrees, depending on flow rate and tubing radius.

Based on a specific pump pressure, technical parameters regarding the well layout and hydraulic properties of the aquifer, the flow rate matching target pump pressure is determined iteratively. In a first step a best guess flow rate is determined, which is used to calculate pressure losses in the loop. Based on the mismatch in the pressure balance, the volume flow rate is updated until convergence in pressure balance has been reached. At a given pump pressure ( $\left.\Delta \mathrm{p}_{\text {pump }}\right), \mathrm{a}_{\mathrm{m}}$ is numerically resolved using the pressure balance and the common secant-method. The pressure balance build-up starts with the static aquifer pressure at the producer (node 1 in Fig. 2). From that node, the pressure and temperature deviations for each succeeding doublet element is calculated at the given pump pressure and mass flow (see Fig. 2). The pressure and temperature deviations can be calculated explicitly for every doublet element except for the wells as these are characterised by a great length. Therefore, the wells are subdivided into segments of $100 \mathrm{~m}$ length. For each segment the equations A10 and A19 are resolved simultaneously by means of the secant method at a given pressure and temperature at the inflow into the well segment. This results in a temperature and pressure at the outflow of the well segment. In this manner pressures and temperatures in all succeeding well segments are iteratively computed. These calculations end up in computation of pressure, temperature, mass flow and volume flow for each node depicted in Fig. 2.

Apart from geothermal output power (Eq. 1), two other key technical output parameters, i.e. required pump power and coefficient of performance (COP), are calculated. The net required pump power (Ppump,net) is a function of the userdefined pump pressure:

$$
P_{\text {pump, net }}=Q_{v} \Delta p_{\text {pump }}
$$

The gross required pump power is the ratio of the net pump power to pump efficiency $(\eta)$ :

$$
\mathrm{COP}=\frac{\mathrm{P}_{\text {pump, net }}}{\eta}
$$

The coefficient of performance (COP) is the ratio between the geothermal power and the gross required pump power and represents a measure of doublet efficiency:

$$
\mathrm{COP}=\frac{\mathrm{P}_{\text {pump, net }}}{\mathrm{P}_{\text {pump, gross }}}
$$

The COP varies as a function of applied pump pressure. For economic reasons, it is common for deep geothermal doublets to adopt a target COP in order to maximise output power and limit parasitic power consumption. A preferred value for COP is 20 , but it can be as low as 10 in particular cases. The calculation routines allow iterative adjustment of the applied pump pressure and the associated flow rate to match the target COP. Pump pressure is however restricted by safety limits to prevent induced seismicity and borehole leakage. To this end, it is assumed that the pressure difference applied at surface conditions for injection and production equals to maximum $2 / 3$ and $-2 / 3$ of the hydrostatic pressure (approx. $100 \mathrm{bar} / \mathrm{km}$ ). In most cases the pressure safety limits are less constraining than the COP limit. Finally a technical limit to applicable pump pressure is assumed. An upper limit of 300 bar for the total pressure difference of the pump has been assumed. Again these limits are in most cases not constraining compared to the COP limit, unless the COP is set below 10 .

\section{Cash flow calculation and economic performance}

Net Present Value (NPV) is defined as the total present value of a time series of cash flows. To calculate NPV the cash flow is discounted back to its present value (PV).

$$
P V=\frac{R_{t}}{(l+i)^{t}}
$$

where:

$t$ the time (year) of the cash flow relative to the start of the project

$i$ the discount rate (the rate of return that could be earned on an investment in the financial markets with similar risk)

$\mathrm{R}_{\mathrm{t}}$ the net cash flow (the amount of cash, inflow minus outflow) at time $t$

The PVs are summed into the cumulative discounted cash flow (CDF) and the NPV is the sum of all yearly terms.

The cash flow is a function of cash in and cash out (Fig. 3). After taking into account the effects of tax, it is discounted and cumulated in order to provide a Net Present Value (NPV) or Unit Technical Cost (UTC). The cash flow is calculated in agreement with the equations developed in the annex. Figure 3 gives an example of NPV calculation for a geothermal project during its (exploration and production) lifetime. Important to note is that produced heat is considered to be sold at an energy price that is equivalent to the market-referenced alternative energy source (e.g. gas). In this way the project is treated as an 


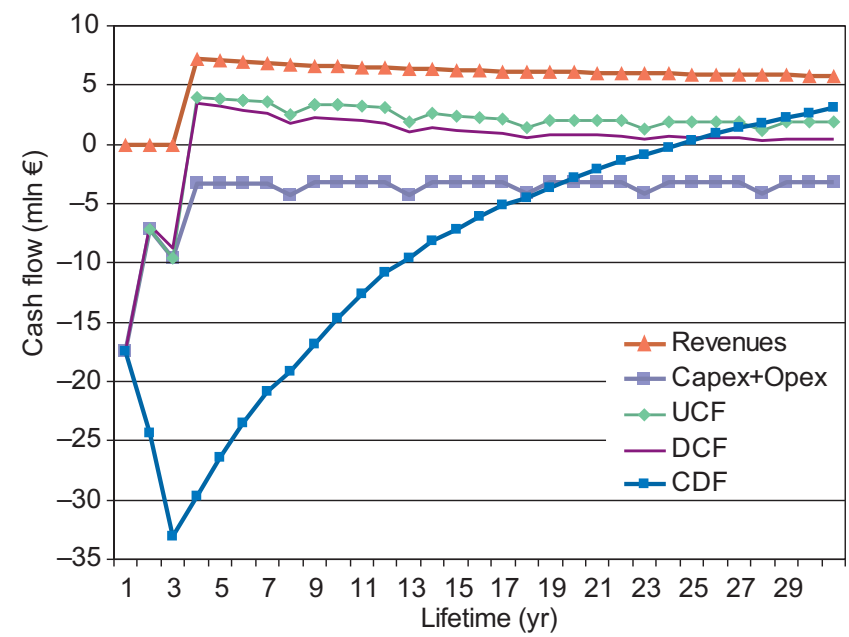

Fig. 3. Cash Flow calculation of an Engineered Geothermal System (EGS) project (from Van Wees et al., 2010) drilled at a depth of $5 \mathrm{~km}$. NPV for the project corresponds to the forecasted Cumulative Discounted Cash Flow (CDF) at the end of the lifetime of the project $(3.1 \mathrm{~m} / \mathrm{n} €)$.

individual investment project. In Fig. 3, the CDF is the accumulation of the discounted cash flow (DCF). The DCF equals the Undiscounted Cash Flow (UCF) corrected for the discount rate. The UCF is the sum of revenues, capital expenditure and operating expenditure (CAPEX and OPEX), corrected for tax. Geothermal cash flow is marked by high CAPEX in first years related to drilling and construction of surface facilities.

Unit Technical Cost (UTC), also known as levelised (discounted) cost of energy (LCOE), is represented by the ratio of accumulated discounted cost over the life time of the doublet and the accumulated discounted energy, e.g. measured in EUR/GJ or EUR/MWth. This parameter allows comparing different strategies of energy production in terms of economic efficiency.

\section{Applications}

Performance calculations integrating technical and economic parameters and underlying uncertainties can be used both for site specific assessment as well as evaluation of regional potential. Below we describe 1) how the methodology can be applied in better understanding of sensitivity of performance to key subsurface parameters and depth trends therein; 2) how it is deployed for assessing the probability of success for geothermal projects for the purpose of insurance and finally 3 ) how the fast model can be used to generate potential maps and cumulative resource estimates. The applications have been limited to greenhouse heating, adopting parameters listed in Table 2.

\section{Depth dependent influence of transmissivity and temperature}

A proper understanding of subsurface conditions and underlying uncertainties is key in geothermal exploration. The power produced by a geothermal doublet is linearly proportional to
Table 2.Default parameters and relationships for the baseline scenario used in DoubletCalc.

\begin{tabular}{|c|c|c|}
\hline $\begin{array}{l}\text { Description } \\
\text { value }\end{array}$ & Unit & Default \\
\hline \multicolumn{3}{|l|}{ Economical parameters } \\
\hline Load factor & - & 0.6 \\
\hline Heat price for sales & EUR/GJ & $11^{1} / 6^{2}$ \\
\hline Electricity price for operations & EURcts/kWh & 8 \\
\hline Heat exchanger costs & mln EUR & 0.1 \\
\hline Well-costs scaling & - & 1.5 \\
\hline Stimulation and base plant costs & mln EUR & 0 \\
\hline Injection/production pump initial costs & mln EUR & 0.5 \\
\hline Fixed OPEX costs & $\%$ & 5 \\
\hline OPEX depending power produced & EUR/GJ & 0 \\
\hline Pump work over costs & mln EUR & 0.25 \\
\hline Pump replacement & years & 5 \\
\hline Tax & $\%$ & 25.5 \\
\hline Discount rate & mln EUR & 7 \\
\hline Funding from the government & mln EUR & $0^{1} / 1.5^{2}$ \\
\hline $\begin{array}{l}\text { Uplift (nr. of years tax deduction can be } \\
\text { transferred to following years) }\end{array}$ & years & 100 \\
\hline Depreciation & years & 10 \\
\hline Energy-Investment deduction (EIA) & $\%$ & 40 \\
\hline Tax rate & $\%$ & 25.5 \\
\hline Number of pumps & - & 1 \\
\hline Coefficient of Performance (COP-target) & - & 15 \\
\hline Economical lifetime & years & $15^{1} / 30^{2}$ \\
\hline
\end{tabular}

\section{Technical parameters}

Skin factor injector

Skin factor producer

Thermal gradient

Surface temperature

Production temperature greenhouses

Re-injection temperature greenhouses

Production temperature spatial heating

Re-injection temperature spatial heating

Inner tubing radius

Tubing's inner diameter

\begin{tabular}{ll}
- & 0.5 \\
- & 2 \\
\hline${ }^{\circ} \mathrm{C} / \mathrm{km}$ & 31 \\
${ }^{\circ} \mathrm{C}$ & 10 \\
${ }^{\circ} \mathrm{C}$ & 45 \\
${ }^{\circ} \mathrm{C}$ & $35^{1} / 25^{2}$ \\
${ }^{\circ} \mathrm{C}$ & 65 \\
${ }^{\circ} \mathrm{C}$ & 40 \\
inch & 3.5 \\
inch & 7.0 \\
inch & 8.0 \\
milli-inch & 1.38 \\
\hline- & 0.6 \\
\hline $\mathrm{m}$ & 100 \\
$\mathrm{~m}^{3} / \mathrm{h}$ & 300 \\
\hline
\end{tabular}

Wells outer diameter

Tubing roughness

Pump efficiency

Aquifer thickness

Maximum pump capacity

$\mathrm{m}^{3} / \mathrm{h}$

300

1 For site specific calculations based on 2012 price levels (Fig. 6). 1 MWth $=3.6 \mathrm{GJ}$. 2 For resource assessment calculation based on 2009 price levels (Fig. 10).

the temperature difference of the produced and reinjected temperature of the percolating brine and the achievable flow rate (Eq. 1). The most important parameter in the calculation of achievable flow rates is the aquifer transmissivity, which is the mathematical product of the permeability and thickness (cf. Eq. 2). In this section we highlight the importance of 
depth-dependent transmissivity and temperature trends, derived from oil and gas data, for performance characteristics in aquifers in the Netherlands.

Clastic aquifers are the prime target for exploration and production in the Netherlands (e.g. Kramers et al., this issue). These aquifers are generally marked by decreasing porosity and associated permeability with depth (Ehrenberg et al., 2009). Generally, a reduction of porosity from about $25 \%$ at $1000 \mathrm{~m}$ depth to about $10 \%$ at $3 \mathrm{~km}$ depth is observed. As a consequence, permeability decreases various orders of magnitude since a linear relationship is often assumed between porosity and the logarithm of permeability (Pluymaekers et al., this issue). The performance of a geothermal doublet is therefore expected to decrease considerably with depth (cf. Eq. 2). On the other hand, as temperature increases with depth, higher temperature differences between injection and production temperature of the brine can be obtained with increasing production depth. This results in a linear increase in performance of a geothermal doublet with depth.

The relationships mentioned above show a trade-off in performance, such that a theoretical optimal depth can be found for a specific temperature gradient, porosity-depth curve and associated porosity-permeability relationship. To illustrate this trade off depth-dependent performance, calculations have been performed for the Rotliegend Group in a prospective region surrounding the Koekoekspolder. We assumed a 100 meter thick aquifer and used average permeability values calibrated to porosity values (Pluymaekers et al., this issue). The porositydepth relationship (Fig. 5) has been derived from all onshore Rotliegend porosity data, corrected for the locally obtained aquifer porosities in the area. Figure 4 shows the adopted porosity-permeability relationship. The resulting depthdependent transmissivity in Fig. 6 indeed shows a pronounced decrease with depth. By assuming the average temperature gradient of $31^{\circ} \mathrm{C} / \mathrm{km}$, adopting parameters listed in Table 2 and iterating applied pump pressure to a COP of 15 , the performance of a geothermal doublet is calculated with increasing depth (Fig. 6). The transmissivity values decrease from $200 \mathrm{Dm}$

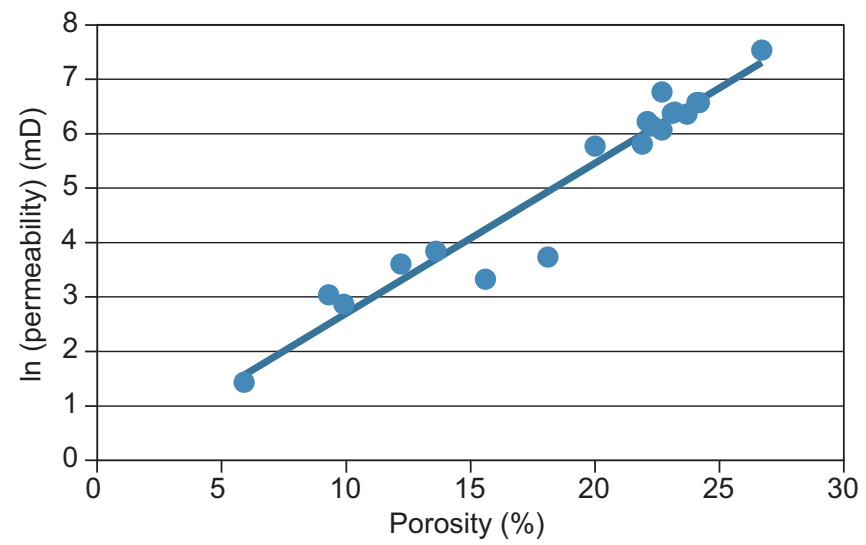

Fig. 4. Porosity-permeability relationship for the Rotliegend Group in the area surrounding the Koekoekspolder.

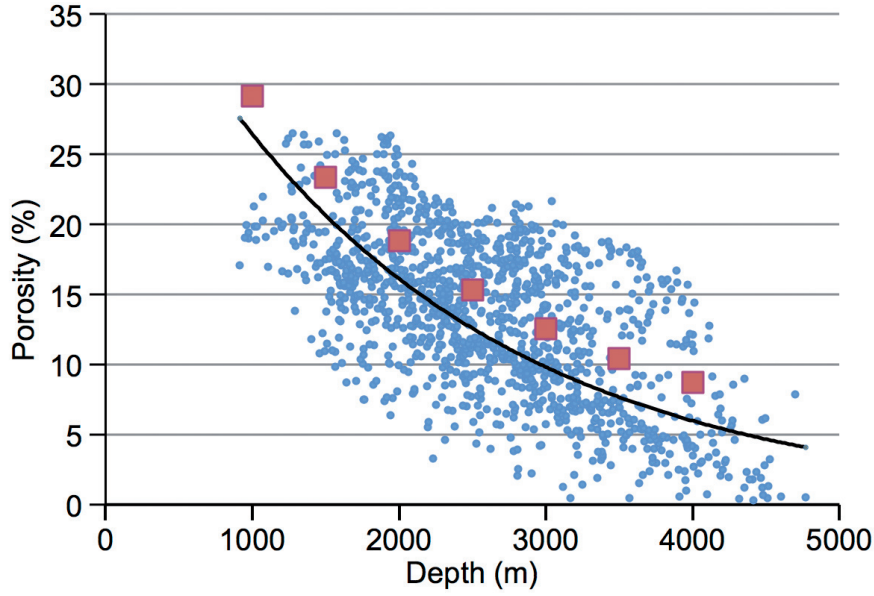

Fig. 5. Porosity-depth relationship (trend line) based on well data from the entire Rotliegend Group derived from mapping porosity (Pluymaekers et al., this issue). Half the standard deviation (red squares) of the porosity in the clastic aquifer in the Rotliegend stratigraphic group surrounding the Koekoekspolder has been included.

at $1000 \mathrm{~m}$ depth to $20 \mathrm{Dm}$ at $2000 \mathrm{~m}$ depth. At $200 \mathrm{Dm}$, hydraulic resistivity and pressure losses of the aquifer are almost negligible and pressure losses due to friction in the pipes limit flow rates. Beyond $2 \mathrm{~km}(20 \mathrm{Dm})$ the lowered transmissivity is dominating the reduction in power through increased hydraulic resistivity in the aquifer. Consequently, at shallow depths temperature rise is dominant, resulting in an increase of power up to 5.07 MWth at a depth of 1.82 kilometres. However, the optimal depth in terms of minimised Levelised Costs of Energy (LCOE) is found at a shallower depth of 1.57 kilometres with 9.03 EUR/GJ. These results clearly show the strong dependence of performance on transmissivity and temperature variation with depth.

Our quantitative assessment is helpful to define bounds of minimum required transmissivity for aquifers. From Fig. 6, it can be observed that for transmissivity values in excess of $30 \mathrm{Dm}$ natural aquifer performance is excellent, whereas below these values the aquifer transmissivity becomes a critical factor and

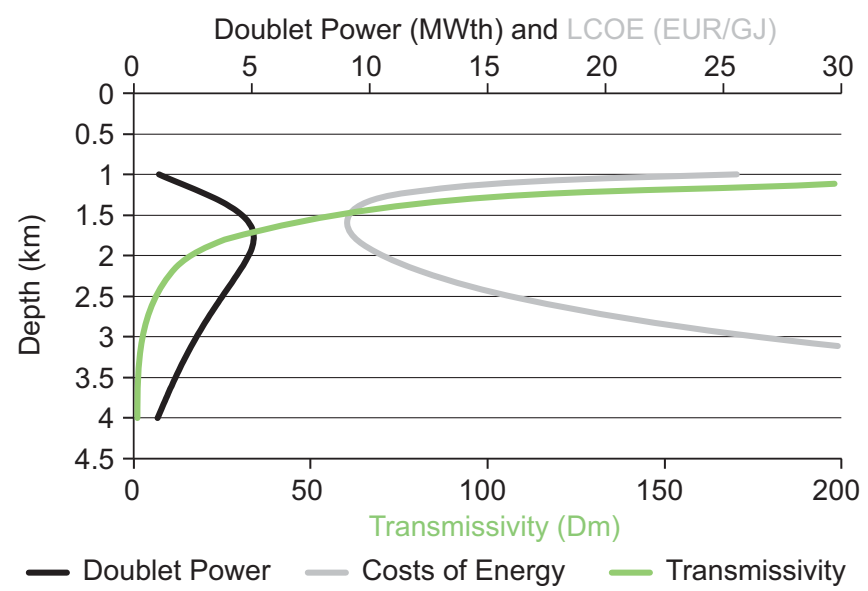

Fig. 6. Optimal depth in doublet power and LCOE modelled with DoubletCalc for an aquifer in the Rotliegend Group. 
may require stimulation or adapted well design. Alternative engineering options such as deviated or horizontal drilling and hydraulic fracking can alter the depth-dependent characteristics. In addition, minimum requirements on production temperature may require targeting deeper aquifers, thus sacrificing doublet power. In addition, the geographical distribution of heat demand only partially overlaps locations where aquifers are at optimum depth, forcing to deviate from an optimum depth. It is beyond the scope of this paper to study in detail technical and economic aspects of these effects.

\section{Sensitivity of model results}

In order to further quantify the influence of temperature and transmissivity we analysed the sensitivity of the model results to variations in technical engineering and economic parameters along with variations in porosity and temperature. Using a Monte Carlo approach, performance in doublet power (MWth) and LCOE (EUR/GJ) has been calculated through changing the input parameters by $\pm 10 \%$. Figure 7 shows the performance calculations, together with the baseline scenario. It is clear that uncertainties in porosity and temperature have the most significant effect on power and LCOE.

\section{Monte Carlo sampling, probability of success and insurance schemes}

The stochastic performance computation in DoubletCalc is carried out via Monte Carlo simulations. The number of simulations can be chosen by the user; 500 to 1000 simulations will deliver sufficient data for a reliable uncertainty assessment and requires moderate computing time. The probability distribution functions (PDF) of the input and output parameters are generated numerically through Monte Carlo sampling. For each simulation run, one sample of any of the input PDFs is selected randomly and used for calculation of the sampled output parameters.

The stochastic output can be displayed in tabular form or screen plots for selected economic and geotechnical output parameters. The probability to comply with a Dutch insurance fund to recover the cost of exploration drilling can be assessed by a cumulative density or so-called expectation plot of predicted power (Fig. 8; SEI, 2011). Within the scope of this insurance scheme, the probability of success (POS) is determined through the probability of predicted power production to exceed a given minimum value, dictated by the business case of the project developer. In the business cases for project developers the threshold power should be financially underpinned by their proprietary cash flow calculations and underlying constraints. Financially, the insurance scheme is aimed to protect the investor from a significant downside risk (cf. Markowitz, 1952; Sharpe, 1964), which equals the average projected NPV for scenarios in which the project is aborted after exploration drilling and negative results for well testing. On the other hand, power can turn out to be much higher than the most likely value. This upside can significantly contribute to a positive NPV outlook, generally capable to compensate for the additional costs of insurance. The Dutch insurance fund requires the POS to be at least $90 \%$. The Doubletcalc version for the insurance scheme does not support automatic adjustment of applied pump pressure to achieve a target COP value. The computation involves a 'base case' for the technical performance assessment, in agreement with median input values. The sensitivity of key parameters of a doublet system can be evaluated by using the 'fingerprint' tool in a numeric and graphical manner (Fig. 9).

\section{Regional resource assessment}

Regional resource assessment is performed in DoubletCalc through 1) the creation of map-based overviews of prospective regions; and 2) the estimation of total amount of geothermal energy which can be extracted from the subsurface. The implications for the prospectivity of subsurface aquifers in the Netherlands and resulting resource potential are presented in Kramers et al. (this issue).

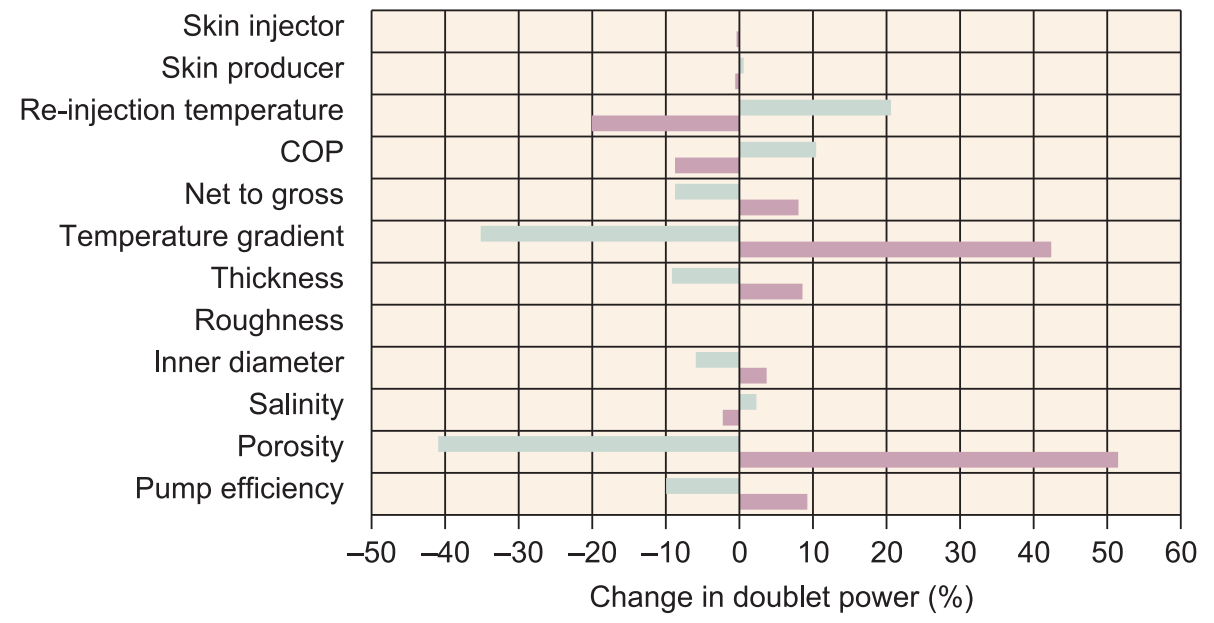

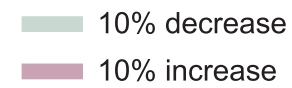

Fig. 7. Tornado plot showing a one-way sensitivity analysis on performance in doublet power. 


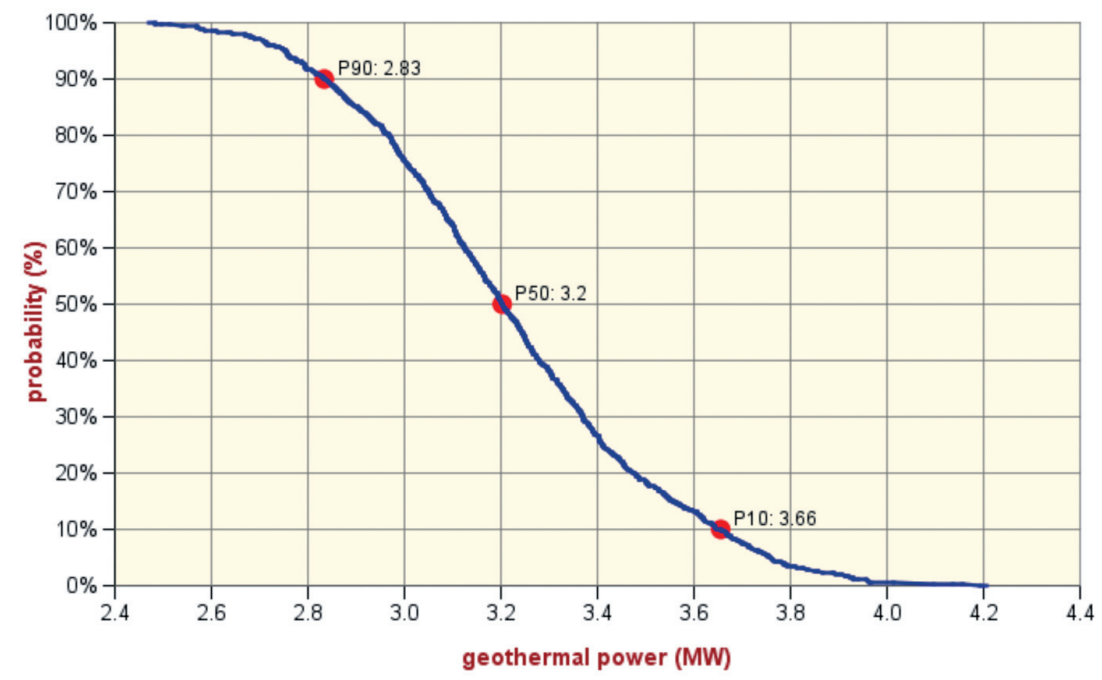

Fig. 8. Example of a stochastic plot of the retrieved Doublet power, displayed as an expectation curve, highlighting the P10, P50 and P90 probability thresholds.
The regional resource assessment relies on the doublet performance calculation using P30 (less likely) and P50 (most likely) values of transmissivity. The spatial resolution of aquifer properties is $500 \mathrm{~m}$. Uncertainties in temperature, depth and well engineering were neglected, because their impact on performance is an order of magnitude lower compared to the uncertainty in transmissivities (see also Pluymaekers et al., this issue). Table 1 lists the parameters for the calculations, which were aiming a target COP of 15.

Using flow rates corresponding to the $\mathrm{P} 50$ value of transmissivity, a minimum well distance has been determined such that a lifetime of 75 years is ensured. This has been done in order for the doublet to sustain at least 2 times higher flow rates, without breakthrough in a lifetime of at least 35 years. This allows to support higher than average aquifer flow rates if performance is better than expected, and to support for earlier than expected thermal shortcut as a consequence of heterogeneous aquifer transmissivity (e.g. due to sealing faults).

Regional prospectivity in terms of power retrieved by a doublet (minimum COP of 15) is illustrated by expected power maps. These maps are differentiated in classes based on the
P30 and P50 power values. The P50 map forms the input; where predicted power is lower than 10 MWth P50 values are replaced by P30 values. The resulting maps have been subdivided in three power potential classes:

- Unknown

- Possible power potential >10 MWth

- Good power potential >10 MWth.

The class 'unknown' corresponds a probability of less than $30 \%$ that the aquifer is present and capable to produce 10 Mwth. The class 'possible power potential' corresponds to a 30\% probability that the aquifer is capable to produce $10 \mathrm{MWth}$ or more. The other class corresponds to a $50 \%$ probability that the aquifer is capable to produce 10 Mwth or more. The large variation in probability is rooted in both the regional approach and the significant uncertainty in transmissivity. More detailed studies and engineering parameters optimised for local circumstances may reduce uncertainty of predicted power at a particular site.

Apart from expected power maps, we calculated potential maps to focus on the economic subsurface suitability for a specific application. These maps have been compiled from the
Fig. 9. Example of a fingerprinting plot, showing the sensitivity of changing pump pressure to base input and output parameters.

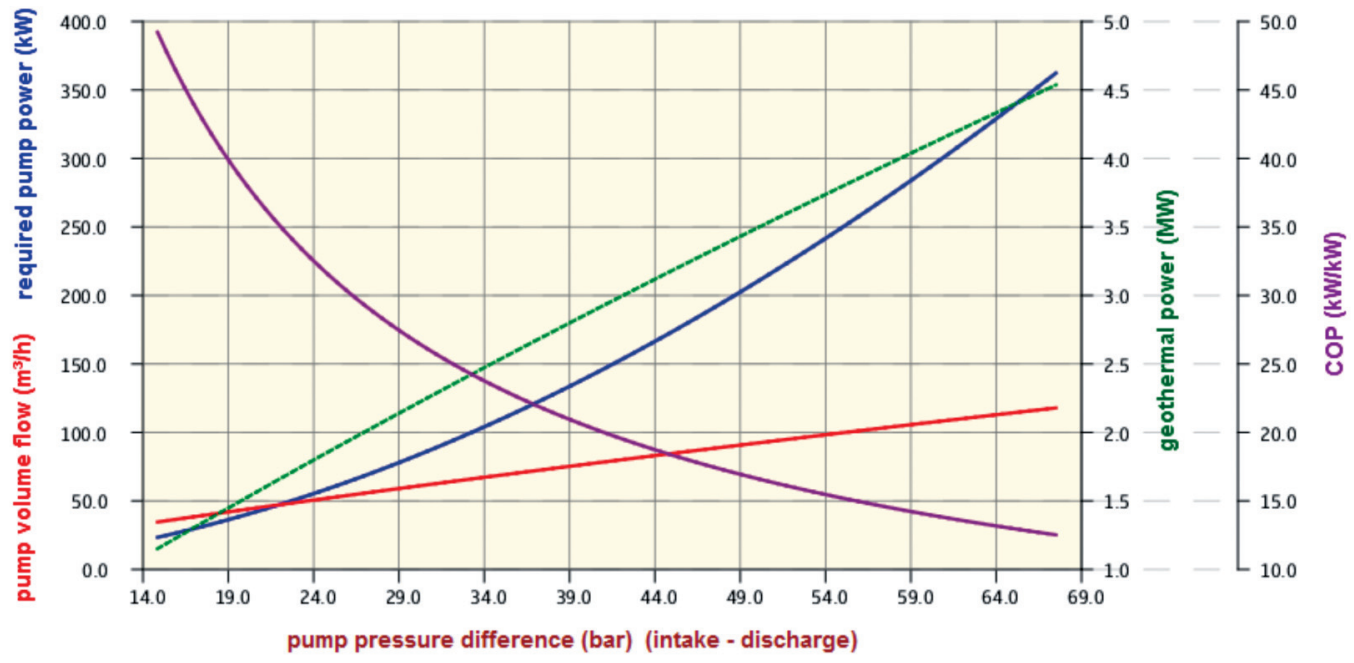

Netherlands Journal of Geosciences - Geologie en Mijnbouw | 91 - 4 | 2012 


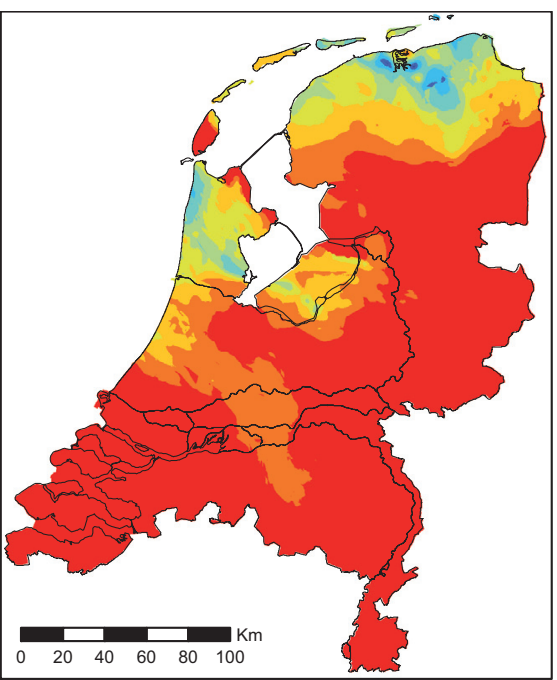

Technical Potential [PJ/km2/y]

$0-0.1$

$0.1-0.2$

$0.2-0.3$

$0.3-0.4$

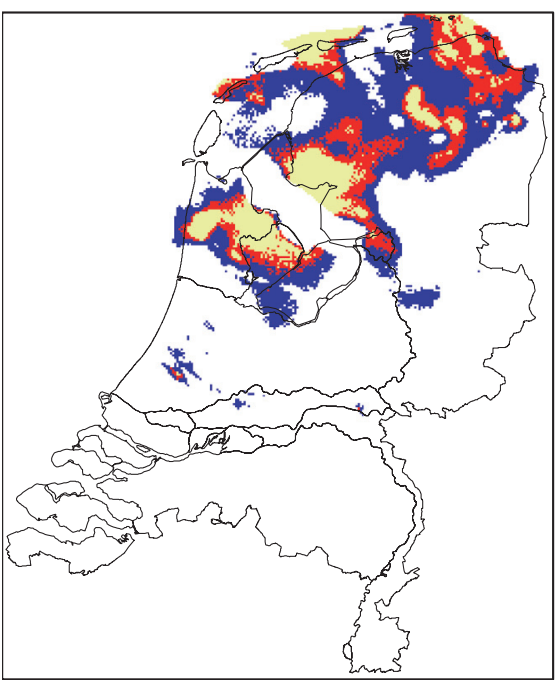

Unit Technical Costs (P50) [euro/GJ]

$\square<4$

$4-6$

$>6$

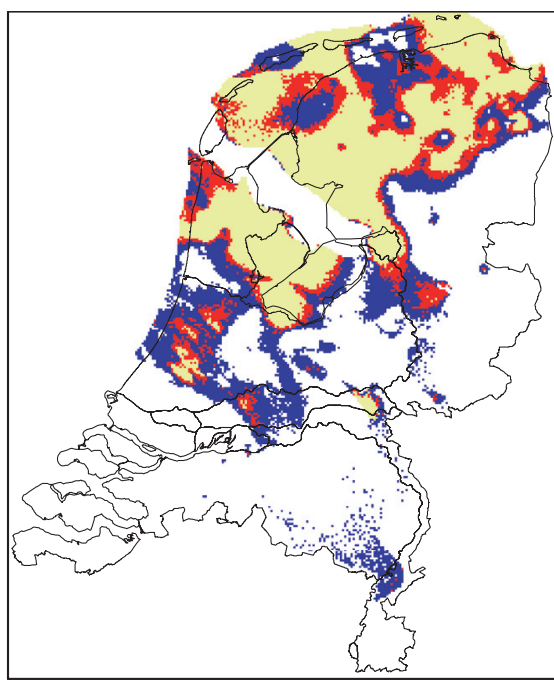

Unit Technical Costs (P30) [euro/GJ]

$\begin{array}{r}\square \\ \square\end{array} 0.4-0.5$

$0.6-0.7$

$0.7-0.8$

$0.8-0.9$

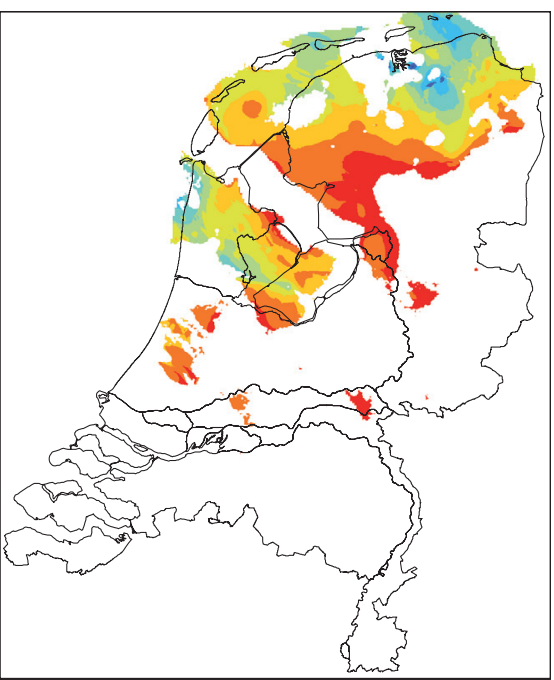

Recoverable heat (P30) [PJ/km2/y] $\square 0.4-0.5$

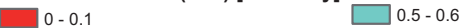

$0.1-0.2$

$0.2-0.3$

$0.7-0.8$

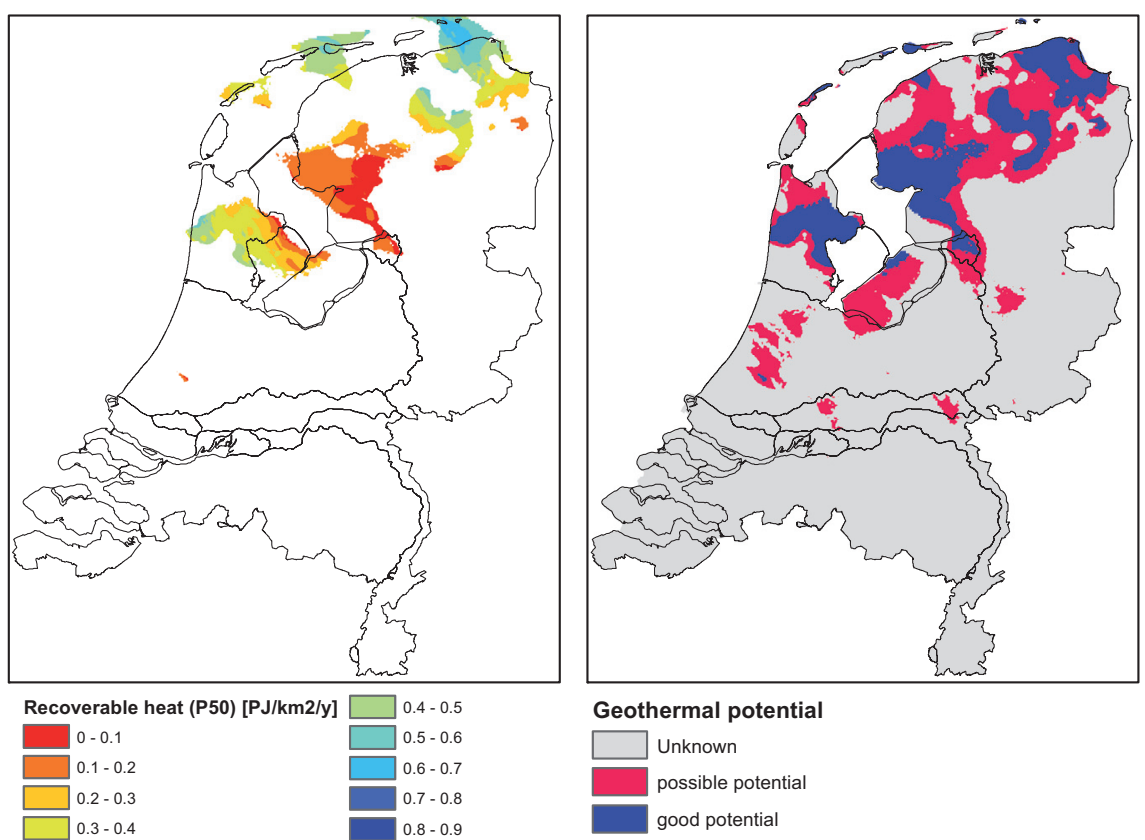

Fig. 10. Example of the calculation procedure applied to one of the major geothermal aquifers in the Netherlands. The maps provide an insight in the geothermal potential at first glance and form a key element in the analysis and presentation of geothermal potential characteristics in ThermoGIS (ThermoGIS, 2011; Kramers et al., this issue).

P30 and P50 map of UTC calculations. The compilation takes the P50 map as input; if the underlying UTC is lower than a threshold value it takes the P30 UTC value as input. The resulting map has been subdivided in three potential classes:

- Unknown

- Possible potential

- Good potential.

The class 'unknown' corresponds to less than $30 \%$ probability that the aquifer is present and capable to develop an economic project (UTC < threshold). The other classes correspond to more than $30 \%$ and $50 \%$ probability that the aquifer is present and capable to develop an economic project (UTC< <hreshold). The expected power and potential maps show a similar patterns. The threshold value has been a value of 6 EUR/GJ (see Table 2).

In recent proposals for geothermal resource assessment (e.g. Beardsmore et al., 2010; IPCC, 2011), a distinction is made between theoretical potential and technical potential. The former describes the total amount of heat in the subsurface (aquifers) which can be used for a particular application, whereas the latter represents the amount of heat which can be extracted. Following Beardsmore et al. (2010), technical potential is 
expressed as a yearly extractable quantity $\left(\mathrm{PJ} / \mathrm{km}^{2} / \mathrm{y}\right)$, adopting a lifetime of 30 years. Such a representation allows matching spatial variability and magnitudes of technical potential with density in heat demand (e.g. Warmte Atlas, 2011) and is highly valuable for policy making purposes. The technical potential is dependent on technical and economic factors. In Beardsmore et al. (2010) no economic evaluations have been made instead technical and economic factors are lumped into a accumulated UR of $1-2 \%$. Here we follow a staged approach in which we first outlined the technical potential, not yet constrained by economics, which is subsequently filtered by project economics to arrive at what we define as recoverable heat.

This approach is illustrated in Fig. 10. As a starting point the theoretical potential for aquifers is calculated and subsequently corrected for a technical ultimate recovery (UR) factor (technical potential). The calculation of the theoretical potential involves a simple volumetric calculation of Heat in Place corrected for application specific constraints of minimum production temperature, return temperature. In Table 2, values have been listed for greenhouse and space heating applications. Technical potential is equal to the theoretical potential multiplied by the ultimate recovery (UR). For the UR it is assumed that, due to legal reasons, a doublet is oriented in a rectangle which encloses the circles centred around the injector and producer well at reservoir level. The circles get into contact half way. In such a doublet layout approximately $50 \%$ of heat enclosed in the rectangle can be technically recovered before thermal breakthrough occurs (cf. Gringarten, 1978). Therefore, the rectangular layout will not be ideal when multiple doublets have to be planned in an area of limited extent and will thus leave unrecovered heat behind. Taking into account these effects, it is assumed that the UR is about $33 \%$. In a next step the technical potential map is filtered to economic constraints resulting in the recoverable heat map. In this process, the volume of rock representing recoverable heat is a subset of technical potential, limited to the region where UTC (evaluated for a specific expected value of transmissivity, see Fig. 10) is lower than a threshold value. An estimate of the national recoverable heat results from an aerial summation of the P50 map.

\section{Conclusions}

The presented probabilistic fast model for performance assessment of geothermal doublets aimed at direct heat applications is a simple and multipurpose tool. It can be applied to better understand performance sensitivity to key subsurface parameters and depth trends therein and for assessing the probability of success for geothermal projects under given technical and financial constraints. A public release (open source) of the software is available under the name of DoubletCalc.

Apart from its application to site assessments the tool can be used to produce indicative maps for predicted doublet power, economic feasibility and prediction of cumulative amounts of recoverable heat. These capabilities are particularly important in decision support for policymakers concerned with assessing the effects of particular insurance schemes and funding mechanisms. It should be emphasised that DoubletCalc software cannot and is not intended to substitute geological exploration. Bearing in mind that exploration measures, such as (2D, 3D) seismic reflection surveys are cost intensive, DoubletCalc can be used to focus geothermal explorations on those areas and sites where an enhanced probability of success can be expected.

\section{Acknowledgements}

This paper benefited from constructive reviews from Pierre Ungemach and Ruggero Bertani.

\section{References}

Batzle, M. \& Wang, Z., 1992. Seismic properties of pore fluids. Geophysics 57: 1396-1408.

Beardsmore, G.R., Rybach, L., Blackwell, D. \& Baron, C., 2010. A protocol for estimating and mapping the global EGS potential. GRC Transactions 34: 301-312.

Beggs, H. \& Brill, J., 1973. A study of two-phase flow in inclined pipes. Journal of Petroleum Technology 25: 607-617.

Dake, L., 1978. Fundamentals of reservoir engineering. Elsevier (Heidelberg, London, New York).

Ehrenberg, S.N., Nadeau, P.H. \& Steen, Ø., 2009. Petroleum reservoir porosity versus depth: Influence of geological age. American Association of Petroleum Geologists Bulletin 93: 1281-1296.

Etherington, J.R. \& Ritter, J.E., 2007. Reserves and Resources Classification, Definitions, and Guidelines: Defining the Standard. Hydrocarbon Economics and Evaluation Symposium (Dallas, Texas, USA).

Fahrshad, F. \& Rieke, H., 2006. Surface-Roughness Design Values for Modern Pipes. SPE Drilling \& Completion 21: 212-215.

Fesitel, R. \& Marion, G., 2007. A Gibbs-Pitzer function for high-salinity seawater thermodynamics. Progress in 0ceanography. D0I:10.1016/j.pocean.2007.04.020.

Garcia-Gutierrez, A., Espinosa-Paredes, G. \& Hernandez-Ramirez, I., 2001. Study on the flow production chrarcteristics of deep geothermal wells. Geothermics 31: 141-167.

Gringarten, A.C., 1978. Well testing in two-phase geothermal wells. 53rd Annual Fall Technical Conference Exhibition (Houston, Texas).

Grunnberg, L., 1970. Properties of sea water concentrations. Third Interantional Symposium on Fresh Water from the Sea, Vol. 1.

Intergovernmental Panel on Climate Change, 2011. Special Report on Renewable Energy Sources and Climate Change Working Group III - Mitigation of Climate Change, $50 \mathrm{pp}$.

Kramers, L., Van Wees, J.-D., Pluymaekers, M.P.D., Kronimus, A. \& Boxem, T., 2012. Direct heat resource assessment and subsurface information systems for geothermal aquifers; the Dutch perspective. Netherlands Journal of Geosciences 91-4: 637-649, this issue.

Markowitz, H., 1952. Portfolio Selection. Journal of Finance 7: 77-91.

Muffler, L.P.J. \& Cataldi, R., 1978. Methods for regional assessment of geothermal resources. Geothermics 7: 53-89.

NLOG, 2009. DoubletCalc: www.nlog.nl/nl/home/DoubletCalc.html. 
Pluymaekers, M.P.D., Kramers, L., Van Wees, J.-D., Kronimus, A., Nelskamp, S.,

Boxem, T. \& Bonté, D., 2012. Reservoir characterisation of aquifers for direct heat production: Methodology and screening of the potential reservoirs for the Netherlands. Netherlands Journal of Geosciences 91-4: 621-636, this issue.

Sharpe, W.F., 1964. Capital Asset Prices: A Theory of Market Equilibrium Under Conditions of Risk. Journal of Finance 19: 425-442.

Subsidieregeling Innovatie en Energie, 2011. www.agentschapnl.nl/nieuws/ regeling-sei-risicos-dekken-voor-aardwarmte-start-1-oktober.

ThermoGIS, 2011. www. thermogis.nl.

Van Everdingen, E.F., 1953. The Skin effect and its influence in the productive capacity of a well. Transactions, AIME 198: 171-176.

Van Wees, J.D., Kramers, L., Kronimus, A., Pluymaekers, M.P.D., Mijnlieff, H.F. \& Vis, G.-J., 2010. ThermoGISTM V1.0, Part II: Methodology: www.thermogis.nl/ downloads/ThermoGISmanual_partII.pdf.

Verruijt, A., 1970. Theory of Groundwater Flow. Macmillan (London), 190 pp.

Warmte Atlas, 2011. Agentschap NL, Dutch Ministry of Economic Affairs. agentschapnl.kaartenbalie. $\mathrm{nl} /$ gisviewer/viewer.do?code $=311$ bc9828c8015a87 e ed3dd8fd179ed8. 


\section{Annex - Performance calculation details}

The impulse balance of the pressure loop of the doublet elements (Fig. 2) is defined by:

$$
\sum_{\mathrm{k}=1}^{\mathrm{N}-1} \Delta \mathrm{p}_{\mathrm{k}+1, \mathrm{k}}+\Delta \mathrm{p}_{1, \mathrm{~N}}=0
$$

$\mathrm{N}$ is defined as the number of nodes $\mathrm{k}$ within the doublet system (see Fig. 2, Table 1); p refers to the pressure (Pa). Concerning the impulse balance, the following equations have been implemented into the code:

$$
\begin{aligned}
& \Delta \mathrm{p}_{\mathrm{k}+1, \mathrm{k}}=\mathrm{p}_{\mathrm{k}+1}-\mathrm{p}_{\mathrm{k}} \\
& \Delta \mathrm{p}_{1, \mathrm{~N}}=\mathrm{p}_{\text {stat }, \mathrm{p}}-\mathrm{p}_{\text {stat }, \mathrm{i}}
\end{aligned}
$$

$\mathrm{p}_{\text {stat, } \mathrm{p}}$ and $\mathrm{p}_{\text {stat, } \mathrm{i}}$ are the initial hydrostatic pressures with respect to the injector and producer, respectively. Substitution of equation $\mathrm{A} 3$ in equation $\mathrm{A} 1$ results in:

$$
\mathrm{p}_{\text {stat, } \mathrm{p}}=\sum_{\mathrm{k}=1}^{\mathrm{N}-1} \Delta \mathrm{p}_{\mathrm{k}+1, \mathrm{k}}-\mathrm{p}_{\text {stat }, \mathrm{i}}=0
$$

In the main text the interaction of the injector and producer with the reservoir has been described. Here, details are given on the pipes. Pressure effects caused within the surface installation are neglected.

The pressure evolution in the pipes is dependent on gravitational forces, friction (viscose force) and inertial forces. The two latter are results of fluid flow. However, as water is barely compressible, the inertial forces are neglected in DoubletCalc. Pipes in a doublet are installed in the wellbores and in the surface facilities. As the pipes in the surface installations generally reveal small lengths and large diameters, their pressure effects have been neglected as well. The pressure evolution of an incompressible fluid within a pipe is revealed by the Darcy Weissbach or Fanning equation (Beggs \& Brill, 1973):

$$
\frac{d p}{d l}=\frac{f \rho v^{2}}{2 D_{\text {in }}}-g \rho \frac{d z}{d l}
$$

where:

$\mathrm{dp} / \mathrm{dl}$ pressure change per well length interval $(\mathrm{Pa} / \mathrm{m})$,

f friction coefficient (-),

$\mathrm{v}$ diameter-averaged stream velocity $(\mathrm{m} / \mathrm{s})$,

$\mathrm{D}_{\text {in }} \quad$ inner tubing diameter of the well (m),

g gravitational acceleration constant $\left(9.80665 \mathrm{~m} / \mathrm{s}^{2}\right)$,

$\mathrm{dz} / \mathrm{dl}$ depth increase per well length interval (-).

The first summand is due to viscous forces, the second due to gravity. The diameter-averaged flow velocity is given by:

$$
\mathrm{V}=\frac{4 Q_{\mathrm{V}}}{\pi \mathrm{D}^{2} \text { in }}
$$

The Reynold's number relates the ratio of inertial forces to viscous forces and is a measure for the turbulence of a fluid stream. Higher Reynold's numbers represent more turbulentprone streaming. It can be used to distinguish between laminar and turbulent streaming. The Reynold's number $\left(R_{e}\right)$ is defined as:

$$
\operatorname{Re}=\frac{\rho v D_{\text {in }}}{\mu}
$$

In case of non-laminar brine streaming $\left(R_{e}>5000\right)$, which is realistic for the operational conditions of doublets due to relative high flow rates combined with small well diameters, the friction coefficient $f$ can be approached by:

$$
f=\left[1.14-2 \log \left(\frac{\varepsilon}{D_{\text {in }}}+\frac{21.25}{R_{e}^{0.9}}\right)\right]^{-2}
$$

where:

$\varepsilon$ roughness of the inner tubing surface (-).

The roughness of the pipes and tubings, respectively $\left(\varepsilon / D_{\text {in }}\right)$ can be retrieved from Fahrshad \& Rieke (2006).

\section{Energy balance}

The energy balance is calculated individually for each element of the doublet system, based on the brine pressure and temperature at the inflow of every element. This calculation results in the revelation of the pressure and temperature at the outflow of each element. The model implies heat exchange at three elements: heat exchanger, producer, and injector. The calculation is initiated at the bottom hole of the producer, based on the geothermal temperature profile. Thereafter, the brine temperature and pressure is calculated for each following element in the direction of flow.

The geothermal temperature profile $\left(\mathrm{T}_{\mathrm{gt}}\left({ }^{\circ} \mathrm{C}\right)\right)$ is represented by the subsurface temperature as a function of depth. This function is further dependent on the surface temperature $\left(\mathrm{T}_{\text {surface }}\left({ }^{\circ} \mathrm{C}\right)\right)$, the geothermal gradient $\left(\lambda\left({ }^{\circ} \mathrm{C} / \mathrm{m}\right)\right)$, and the averaged aquifer depth at the producer $(\mathrm{d}(\mathrm{m}))$ :

$$
\mathrm{T}_{\mathrm{gt}}=\mathrm{T}_{\text {surface }}+\lambda \mathrm{d}
$$

The heat exchange between the wells and the surrounding geosphere is calculated as energy per length unit $(\mathrm{W} / \mathrm{m})$. In the producer the brine experiences usually a heat loss due to the averaged relative colder geosphere, while brine heating can occur in the injector. Such heat exchange is calculated according to Garcia-Gutierrez et al. (2001):

$$
\mathrm{q}_{\mathrm{h}, \text { well }}=\frac{4 \pi \mathrm{k}_{\mathrm{t}, \mathrm{r}}\left(\mathrm{T}_{\mathrm{c}}-\mathrm{T}_{\mathrm{r}}\right)}{\ln \left(\frac{4 \mathrm{a}_{\mathrm{t}, \mathrm{r}} \mathrm{t}}{\sigma \mathrm{r}_{\mathrm{c}}^{2}}\right)}
$$


where:

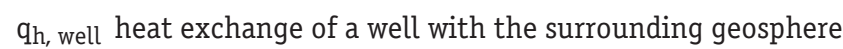
$(\mathrm{W} / \mathrm{m})$

$\mathrm{k}_{\mathrm{t}, \mathrm{r}} \quad$ thermal conductivity of the rock surrounding the wells $(\mathrm{W} /(\mathrm{mK}))$

$\mathrm{T}_{\mathrm{C}} \quad$ temperature of the casing $\left({ }^{\circ} \mathrm{C}\right)$

$\mathrm{T}_{\mathrm{r}} \quad$ temperature of the rock $\left({ }^{\circ} \mathrm{C}\right)$

$\alpha_{t, r} \quad$ thermal diffusion coefficient of the aquifer lithology $\left(\mathrm{s} / \mathrm{m}^{2}\right)$

t heat exchange duration (s)

$\sigma \quad \mathrm{e}^{\mathrm{Y}}=1.781072$, using Euler's constant $\mathrm{Y}=0.577216$

$\mathrm{r}_{\mathrm{c}} \quad$ radius of the well casing $(\mathrm{m})$

The thermal diffusion coefficient of the surrounding lithology is retrieved by ( $\rho_{\mathrm{g}}$ : rock density, $c_{\mathrm{W}, \mathrm{r}}$ : heat capacity of the rock surrounding the wells):

$$
\alpha_{t, r}=\frac{k_{t, r}}{\rho_{g} c_{w, r}}
$$

The thermal conductivity $\left(\mathrm{k}_{\mathrm{t}, \mathrm{g}}\right)$ of the surrounding lithology is assumed to be $3 \mathrm{~W} /(\mathrm{mK})$. In DoubletCalc, heat exchange with the surrounding geosphere is assumed to be near equilibrium one year after launching doublet operations. Thus, in equation $16 \mathrm{t}$ is fixed at $\mathrm{t}=1$ year.

The energy balance requires the energy of the brine temperature change equals the correspondent heat energy change in the surrounding geosphere:

$$
\mathrm{q}_{\mathrm{w}, \text { well }}=\mathrm{Q}_{\mathrm{m}} \mathrm{c}_{\mathrm{p}} \frac{\mathrm{dT}_{\mathrm{well}}}{\mathrm{dl}}
$$

where:

$c_{p} \quad$ brine heat capacity $(\mathrm{kJ} / \mathrm{kg} / \mathrm{K})$

$\mathrm{dT}_{\mathrm{well}} / \mathrm{dl}$ temperature modification rate per well segment due to heat exchange $(\mathrm{K} / \mathrm{m})$

Re-organising equation 18 results in:

$$
\frac{\mathrm{dT}_{\text {well }}}{\mathrm{dl}}=\frac{\mathrm{q}_{\mathrm{h}, \text { well }}}{\mathrm{a}_{\mathrm{m}} \mathrm{c}_{\mathrm{p}}}
$$

Considering a typical doublet, heat loss in the producer can be of 1-3 $\mathrm{K}$ and results in a reduction of the geothermal output power. In the injector brine heating usually results in a temperature rise smaller than $1 \mathrm{~K}$. There, the sole impact is the modification of the brine's viscosity.

The temperature drop $\left(\Delta \mathrm{T}_{\mathrm{ww}}\right)$ in the heat exchanger is quantified by:

$$
\Delta \mathrm{T}_{\mathrm{ww}}=\mathrm{T}_{\mathrm{ww}, \text { in }}-\mathrm{T}_{\mathrm{ww}, \text { out }}
$$

The inflow temperature into the heat exchanger $\left(\mathrm{T}_{\mathrm{ww}, \text { in }}\right)$ equals the outflow temperature of the producer. The outflow temperature of the heat exchanger $\left(\mathrm{T}_{\mathrm{ww}, \text { out }}\right)$ equals the injection temperature. Heat loss in the surface pipes and the efficiency of the heat exchanger are neglected. Tww, outis a user-defined input parameter in DoubletCalc.

\section{Brine properties}

The following brine properties are calculated by DoubletCalc for the geotechnical performance assessment: density, viscosity, heat capacity and salinity. The equations implemented therefore are described below. It has to be noted those equations are partly based on non-SI units. Freshwater $\left(\rho_{\mathrm{fw}}\right)$ and brine densities are applied in $\mathrm{g} / \mathrm{cm}^{3}$ and the viscosity in centi Poise $(\mathrm{cP})$. Brine densities are calculated according Batzle \& Wang, (1992):

$$
\begin{aligned}
\rho_{\mathrm{fw}}= & 1+10^{-6}\left(-80 \mathrm{~T}-3.3 \mathrm{~T}^{2}+0.00175 \mathrm{~T}^{3}+489 \mathrm{p}-2 \mathrm{Tp} \quad(\mathrm{Eq} . \mathrm{A} 15)\right. \\
& \left.+0.016 \mathrm{~T}^{2} \mathrm{p}-1.3 \cdot 10^{-5} \mathrm{~T}^{3} \mathrm{p}-0.333 \mathrm{p}^{2}-0.002 \mathrm{Tp}^{2}\right)
\end{aligned}
$$

The temperature (T) is applied in ${ }^{\circ} \mathrm{C}$.

$$
\begin{aligned}
\rho= & \rho_{f w}+s\left\{0.668+0.44 s+10^{-6}[300 p-2400 p s\right. \\
& +T(80+3 T-3300 s-13 p+47 p s)]\}
\end{aligned}
$$

Viscosities are calculated using the following equation (Batzle \& Wang, 1992):

$$
\begin{aligned}
\mu= & 0.1+0.333 \mathrm{~s}+ \\
& \left(1.65+91.9 \mathrm{~s}^{3}\right) \exp \left(-\left[0.42\left(\mathrm{~s}^{0.8}-0.17\right)^{2}+0.045\right] \mathrm{T}^{0.8}\right)
\end{aligned}
$$

The brine's heat capacity $\left(c_{p}\right)$ is a function of temperature, salinity and pressure ( $\mathrm{s}$ : salinity $(\mathrm{g} / \mathrm{kg})$ ). In DoubletCalc the heat capacity of formation brine is approached based on polynomials according to Grunnberg (1970). Although it may appear this source may be somewhat out of date, Grunberg is cited in more recent publication and is considered a reliable resource (Fesitel \& Marion, 2007). Following Grunberg, the heat capacity of brine can be approached using:

$$
\begin{aligned}
\mathrm{cp}= & \left(+5.328-9.760 \cdot 10^{-2} \mathrm{~s}+4.040 \cdot 10^{-4} \mathrm{~s}^{2}\right) \\
& +\left(-6.913 \cdot 10^{-3}+7.351 \cdot 10^{-4} \mathrm{~s}-3.150 \cdot 10^{-6} \mathrm{~s}^{2}\right) \mathrm{T} \\
& +\left(+9.600 \cdot 10^{-6}-1.927 \cdot 10^{-6} \mathrm{~s}+8.230 \cdot 10^{-9} \mathrm{~s}^{2}\right) \mathrm{T}^{2} \\
& +\left(-2.500 \cdot 10^{-9}+1.666 \cdot 10^{-9} \mathrm{~s}-7.125 \cdot 10^{-12} \mathrm{~s}^{2}\right) \mathrm{T}^{3}
\end{aligned}
$$

Note, the $6^{\text {th }}$ coefficient is published with an incorrect sign $\left(+3.15 \cdot 10^{-6}\right.$ instead of $\left.-3.15 \cdot 10^{-6}\right)$ in Grunberg (1970).

Considering salinity there are two regimes present:

- Static: the initial static equilibration in the subsurface.

- Dynamic: during production within the doublet.

The initial static equilibrium is a function of depth (d) and based on the production aquifer top depth $\left(d_{t o p}, p\right)$, the aquifer thickness $(H)$ and the salinity of the aquifer $\left(s_{a q}\right)$ :

$$
s(d)=s_{a q} \frac{d}{d_{t o p, p}+0.5 H}
$$


The aquifer brine pumped through the doublet system during operations is characterised by a constant salinity:

$$
\mathrm{s}=\mathrm{s}_{\mathrm{aq}}
$$

\section{Cash flow calculations}

In DoublectCalc, the Cash-in (mln EUR/yr) for a single year is given by the (virtual) heat sale.

$$
\mathrm{C}_{\text {cash_in_year }}=\mathrm{C}_{\text {heat_year }}
$$

$C_{\text {heat_year }}$ relates to the Selling price of heat $E_{\text {heat_price_sell }}$ (EUR/GJ) and the heat which is produced:

$C_{\text {heat_year }}=M W_{\text {heat_gross }} R_{\text {running hrs } / y r} 3600$ Eheat_price_sell $10^{-3}$

where $\mathrm{MW}_{\text {heat_gross }}$ is thermal power of the doublet. $\mathrm{R}_{\text {running hrs/yr }}$ has been calculated from a load factor multiplied to the number of hours in a year:

$$
\mathrm{R}_{\text {running hrs } / \mathrm{yr}}=\mathrm{L}_{\text {load factor }} 8760
$$

\section{Cash out}

The Cash-out consists of Capital Expenditure items (CAPEX), Operational Expenditure (OPEX), royalties and Tax.

$$
\mathrm{C}_{\text {cash_out_year }}=\mathrm{E}_{\text {capex_year }}+\mathrm{E}_{\text {opex_year }}+\mathrm{E}_{\text {tax_year }}
$$

CAPEX is related to investments made for the heat exchanger, well stimulation - if any - and other costs. These are one or more of the following terms depending if they are built in the specific year.

$$
\begin{aligned}
\mathrm{E}_{\text {capex_year }}= & 2 \mathrm{E}_{\text {capex_well }}+\mathrm{E}_{\text {stimulation_other costs }} \quad \text { (Eq. } \\
& +\mathrm{E}_{\text {capex_heat exchanger }}+\mathrm{n}_{\text {pump }} \mathrm{E}_{\text {capex_pump }}
\end{aligned}
$$

The number of pumps is assumed to be one.

The capex items have been assumed fixed except well costs. For the wells the capex has been scaled to drilling depth $z_{\mathrm{r}}(\mathrm{m})$ (Fig. 4):

$$
\mathrm{E}_{\text {capex_well }}=\mathrm{E}_{\text {well cost scaling }}\left(0.2 \mathrm{Z}_{\mathrm{R}}{ }^{2}+700 \mathrm{Z}_{\mathrm{R}}+25 \cdot 10^{3}\right) 10^{-6}
$$

OPEX relates to yearly operation costs for the plant and wells, consumption of electricity and refurbishment of pumps. A fixed percentage ( $\left.E_{\text {opex_fixed }}\right)$ and variable opex ( $\left.E_{\text {opex_variable }}\right)$ as a function of heat produced have been used:

$$
\begin{aligned}
E_{\text {opex_year }}= & E_{\text {capex_active }} E_{\text {opex_fixed }} \\
& +M W_{\text {heat_produced_gross }} E_{\text {opex_plant_variable }} \\
& +n_{\text {pump }} E_{\text {refurbishment_pump }} \\
& +e_{\text {pump }} R_{\text {running hrs } / y r} 3600 E_{\text {price_buy }} 10^{-8}
\end{aligned}
$$

$\mathrm{e}_{\text {pump }}$ is power consumption (kWh) calculated by doubletcalc.

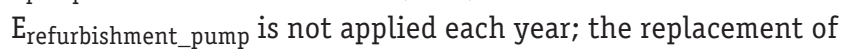
the pump occurs only every few years (default value every 5 years). This time between two replacements is given by Eyears_for_fit.

Taxable income is calculated as:

$$
\begin{aligned}
E_{\text {taxable_year }}= & \operatorname{Max}\left(C_{\text {cash_in_year }}-C_{\text {cash_out_year }}\right. \\
& \left.-E_{\text {deductable_capex }} 0\right)
\end{aligned}
$$

The deductible capex follows a SCLA (Straight Line Capital Allowance: Each capex item is depreciated in equal parts over the specified number of years).

Costs for tax deduction (e.g. investments prior to revenues especially at the start of the project) can be transferred to a number of following years, determined by $\mathrm{C}_{\text {uplift. }}$. It is recommended to use a number equal to the lifetime of the project, meaning that cost can be deducted always as soon as revenues occur. An exception is made in the case of $\mathrm{C}_{\text {uplift }}=0$. In this case it is assumed that corporate tax compensation occurs through profits elsewhere in the company. The resulting tax reduction is taken into account as additional income when cash flow is negative.

Tax is a fixed percentage of the taxable income, resulting in the yearly cash flow:

$$
\begin{aligned}
& E_{\text {tax_year }}=E_{\text {taxable_year }} E_{\text {tax }} \\
& E_{\text {income_after_tax_year }}=E_{\text {taxable_year }}-E_{\text {tax_year }}
\end{aligned}
$$

\section{Phasing of cash in and cash out}

The CAPEX terms are made before the first heat is produced (yfirst_heat), typically various years after the evaluation start (yevaluation). The time for the evaluation ( $\left.t_{\text {evaluation }}\right)$ is followed by the drilling of the wells, which are assumed to be drilled within a year. Possible lagging times ( $t_{\text {lagging }}$ ) precede a number of years required to build the heat exchanger.

$$
\text { Yfirst_heat }=\text { yevaluation }+t_{\text {drilling }}+t_{\text {lagging }}
$$

\section{Discounted cashflow, NPV and UTC}

The discounted cashflow is calculated as:

$$
E_{\text {income_discounted_year }}=\frac{E_{\text {income_after_tax_year }}}{\left(1+E_{\text {discount rate }}\right)^{(\text {year-y }}}
$$

The Net Present Value is calculated as the sum of the discounted income:

$$
\mathrm{NPV}=\sum_{\text {year }=\text { yevaluation }}^{\text {year }=\text { economic lifetime }} E_{\text {income_discounted_year }}(\text { Eq. A32) }
$$


Unit technical cost (UTC), also known as levelised cost of energy (LCOE) is represented by the total cost over the life time of a heat providing asset related to the provided energy. The calculation of the UTC gives the opportunity to compare different energy providing technologies to each other and to the prices which are paid on the energy markets. For geothermal energy, its calculation is based on the estimation of site- and project-specific conditions on power which can be produced, electricity consumption by pumps. The Unit Technical Cost is calculated as the ratio of: a) the cumulative discounted yearly Cash-out; and b) the cumulative discounted heat produced. 